\title{
Corporate Governance on the National Olympic Committee of Thailand
}

\author{
Suriyan Somphong1 ${ }^{*}$, Supitr Samahito ${ }^{2}$, Issadee Kutintara ${ }^{3}$ \\ ${ }^{1}$ Faculty of Sports Science, Kasetsart University, Kamphaeng Saen Campus, Nakhon Pathom, Thailand \\ ${ }^{2}$ National Olympic Committee of Thailand, Bangkok, Thailand \\ ${ }^{3}$ Sport Management Department, Faculty of Sports Science, Kasetsart University, Kamphaeng Saen Campus, \\ Nakhon Pathom, Thailand \\ Email: "ssomphong@yahoo.com
}

Received 15 May 2015; accepted 19 December 2015; published 22 December 2015

Copyright (C) 2015 by authors and Scientific Research Publishing Inc.

This work is licensed under the Creative Commons Attribution International License (CC BY). http://creativecommons.org/licenses/by/4.0/

(c) (i) Open Access

\section{Abstract}

The Olympic Games is by far the most admirable competitions among athletes and the most spectacle sports tournaments among sports fans. The Olympic Games is built on their very core values when the games bring together people around the world to witness one of the amazing sports events in the world. It is a congregation of the Olympic Games. Three core values, i.e., excellence, friendship and respect, are around the world. The immense role of the dissemination of Olympic values and promoting and overseeing the Olympic Games falls on the shoulder of the International Olympic Committee (IOC) which is a decision-making organization regarding the Olympic affairs. Though a huge responsibility lied upon the IOC, the IOC alone cannot operate and function at this successful level. The National Olympic Committees (NOCs) from various countries need to provide considerable support to the IOC, and the accomplishment of the IOC's objectives can be achieved only if the NOCs work efficiently and effectively. The NOCs perform various functions and provide a significant contribution to promoting sports in a country. Thailand is one of the IOC members. The missions of the National Olympic Committee of Thailand (NOCT) under the Royal Patronage of H.M. the King include supporting and promoting amateur sports and physical education, sending delegated athletes and the international. Competitions, providing welfare and education for athletes and coaches, organizing a sports museum, and coordination with different management of the NOCT are highly essential. Effective management of the NOCT will lead not only to the increasing number of junior athletes and national athletes and the success of our national athletes in major international sports competitions, but also to gear Thailand to be a healthy society using sports as a means to this end. In business, it is often argued that effective management is caused by competition. The term "creative destruction" coined by Joseph Schumpeter has continuously been proven through time that the most effective and innovative firms will thrive. Without competition, there is no real incentive and need for firms to be effective and efficient. Firms can do whatever

"Corresponding author. 
they want bearing few or no consequences. Many sports governing bodies, e.g. the IOC and the NOCs, however, have no competition and, thus, are a monopoly. Yet, thee organizations need to be most effective. In this paper, we will argue that corporate governance is the solution to make the NOCs and the IOC to be most effective by using an example of the NOCT. Corporate governance (CG) can be loosely defined as to how to institute integrity to organizations/industries. Similar to business, the IOC and the NOCs need to instill integrity to their members no matter who they are or what role they take. A cleverly tailored corporate governance process employing control from both top-down and bottom-up will provide a necessary means to make the NOCs or, in this paper, the NOCT becomes well managed.

\section{Keywords}

\section{Corporate Governance, National Olympic Committee, Olympic Movement}

\section{Introduction}

Education is the core of the Olympic Movement, because all of the fundamental roles entrusted to the movement depend entirely on the educational values of the Olympic Movement. For that reason, all the key figures of Olympism put great emphasis on education. Pierre de Coubertin (1997) [1], the founder of the modern Olympic Movement and inspired educator, fully recognized the importance of education and said "Olympic Education and the Olympic Spirit have the power to contribute to resolving some of the most intensive social problems and teaching principles of honesty and respect.” Thus to him, the Olympic Movement areas, in essence, are a tool for education.

Juan Antonio Samaranch, Honorary IOC President, also indicated that "The wealth of people and countries lies in education, and sports play a major role in provide a lesson for life and should be a point of reference for youths. It is an appeal for the unity of people and for place” (IOC, 1994) [2]. While Jacques Rogge, IOC President showed his feeling about the sports as "Sport plays an important role in integration by contributing to the adoption of values such as respect and tolerance; he's also made a conclusion that this should be the legacy of the Olympic Games”. Looking at the Olympic Motto, Dr. Nikos Filaretos, IOA President, said that “"Citius-AltiusFortius' was meant for every youngster to be, faster in sport performance and perception, higher in moral standing and stronger in fortitude for the struggle life”.

Olympic Education, in general, is the process by which people learn Olympism. With respect to pedagogy, Olympic Education is the grass root for general education. Dr. Lambis Nikolaou, President of Hellenic Olympic Committee said that, "Education is the corner stone of the Olympic Movement; its goal is to contribute to building a peaceful and better world, by educating youth through sport, without discrimination and in the Olympic Spirit, which require mutual understanding with a spirit of friendship, solidarity and fair play”.

We bring all of those messages to share with all of you today because of fearing that in the near future the power of the spiritual inspiration of the Olympic Movement may be slipping away while an orientation to material values has quickly developed, which has brought the serious problems to the Olympic Movement. Anyway, we still believe that the status of the National Olympic Committees has profound influence on the Olympic Movement because they are responsible for delivering Olympic knowledge and promoting the Olympic spirits and ideals.

In the last decade, NOCT providentially began activities in Thailand. These activities include workshops and seminars as well as the youth activities that are applied in order to promote the Olympic idea in Thailand. Olympism that was long forgotten began to enliven again by the TOA. In this connection, Thai people, particularly the youngsters, have opportunities to acquire the idea of Baron Pierre de Coubertin and Chao Phraya Dharmmasakmontre. Their common quest is to build a peaceful society with knowledgeable people with strong body and mind. With the TOA lead, a goal is set to be achieved with a constructive plan. Thai youngsters should be able to understand the value, idea and principal of Olympism. It is aimed to inspire the society by using the Olympic philosophy in developing the young ones in the future. With the inspiration, legacy that was lost long ago should then be installed into the society once again. 


\section{Corporate Governance in Sports Governing Bodies}

Since the turn of the century, corporate governance (CG) has become a very serious issue due to the collapse of several big companies. CG pertains to explicit rules, laws or procedures, and implicit cultures in which and by which there is a conflict of interests between different parties in an organization. It aims to protect minor shareholders from the appropriation of major shareholders or managers in a company (Claessens \& Fan, 2002, Mitton, 2002) [3]. A good established CG practice is believed to offer a solution to scrupulous management (Cato Institute, 2003) [4].

CG for sports governing bodies, especially the IOC and NOCs, is very serious issue for three obvious reasons. First, since the IOC and the NOCs are organizations which need to balance the interests of many different types of parties. The IOC needs to find a mutual agreement or interest form an individual (e.g., athletes, coaches, referees) to a country (e.g., NOCs or Olympic bidding countries) and form a nonprofit organization (e.g. International Sports Federation or UN agencies) to a profit organization (e.g., sponsors or broadcasting companies). The NOCs have the same burden as the IOC but at a smaller scale. With this difficult task, a conflict of interest can easily occur, e.g. the Fasel cast in 2009 where he was reprimanded by the IOC, or possible concerns for two sponsorship agreements of the South Korean bid for the Winter Olympic Games in 2014.

Secondly, the IOC and the NOCs are monopolistic organizations in their domain. The right to decide which country will host the Olympic Games belongs only to the IOC, while the right to send athletes to participate in the Olympic Games belongs only to the NOCs. Because of this monopolistic nature, the need for good CG is extremely important because without competition the need for improvement, adaptation, or effective management is minimal. This may lead to ineffective management of the IOC, unfair and/or dangerous competitions. Lastly, CG is highly essential for the IOC and the NOCs because of the role bestowed upon the IOC and the NOCs. It is the task of the IOC and the NOCs to encourage support and use sports as a tool to promote peace, fair play, health, and social equality among different races and genders.

Friedman (1999) and Zakus (2000) [5] argued for the immediate needs of corporate governance and of management paradigm shift for the IOC. The Governance is Sport Working Group (2001) [6] provided a guideline for good governance. The guideline includes nine principles, as follows:

1) The role of the governing body pertains to how sports governing bodies (SGB) govern their stakeholders to the best interest of their sports domain. The role of SGB, thus includes how SGBs enact, establish, and enforce rules of the games as well as promote and represent its sports.

2) Structure, responsibilities, and accountability are roles and responsibilities of groups of SGBs.

3) Membership and size of the governing body pertain to the number and qualification of members of SGBs and how SGBs operate.

4) Democracy, elections, and appointments deal with the process of acquiring member of SGBs.

5) Transparency and communication cover how SGBs communicate with their members. Thus, it provides a good in indicator showing the quality of good governance.

6) Decisions and appeals pertain to how the process that SGBs settle disputes and derive their decisions as well as the process of appeals.

7) Conflicts of interest ensures that every member of SGBs act to the best of their interest. Hence, clear demarcation is encouraged.

8) Solidarity deals with how SGBs appropriately distribute their financial revenue. As a result, it is very important to the development of sports.

9) Recognition of other interests: SGBs are required to recognize other special interest groups which may affect the decisions and interests of SGBs.

Instead of nine principles, Burger \& Goslin (2005) [7] summarized that seven values were required in order to successfully have good governance sports organizations. Seven pillars of good governance for sports organizations include: 1) fairness 2) accountability 3) responsibility 4) transparency 5) social responsibility 6) independence and 7) discipline.

\section{Olympic Movement in Thailand}

Thailand recognizes the results of the Olympic Movement as the cooperation of internal and international sport development for human better lives. Utilization of sport as means of personal efficiency development because sporting and exercising are the means to develop physical, mental principles which reflect to individual and so- 
ciety existing and also national reputation. The quotation from our Great Sport King Rama IX, "Sport is the most significant to individual and nation lives with correct conducting, with efficiency and capability, of which will gain reputation to oneself and the country, if conducted with politeness will also gain the same reputation and national unity"

Sport in Thailand has been promoted and developed by public and private sectors long time ago. The Department of Physical Education was established in 1933 for the promotion of sport and physical education to pupil and youth in school, while the Sport Authority of Thailand (SAT) was established in 1967 for coordination and promotion of sport among people and young all over the country. Government also has a policy for local and central government agencies to promote sport and exercise for their own personal.

National Sport Development Plan is the master plan to indicate policy, direction and boundary of sport development and promotion for sport organization including organizations e.g. Sport Authority of Thailand, Physical Education Department and National Olympic Committee of Thailand, etc. This Master Plan consists of 6 developments as the development for fundamental exercise and sport, the development for mass sport, the development for elite sport, the development for professional sport, and the development for technology and sport science and development for sport management, National Sport Development Plan coverage 2012-2016. The improvement of Thailand sports development is indicated by the number of medals gained in SEA Games, Asian Games and Olympic Game. At the regional in the Asian world to host the Asiad for 4 times in 1966, 1970, 1978 and 1998 and 6 times for SEA Games in 1959, 1967, 1985, 1995 and 2007 also we have bidding for hosting the Summer Olympic Games in 2008.

The National Olympic Committee of Thailand under the Royal Patronage of H.M. the King (NOCT) was established on June 20, 1948, was granted his Royal Patronage by His Majesty King Bhumipol Adulyadej on December 26, 1949 and was unanimously approved form recognition by the IOC on May 15, 1950 at its IOC General Assembly Session in Copenhagen, Denmark. Headquarter is in Bangkok. For the beginning its working, the first four sport associations affiliated to the National Olympic Committee were the Football, Lawn Tennis, Rugby Football as well as the Athletics Association. Currently there are 33 Sport Associations under the umbrella of NOCT.

The structure of the NOCT consists of one executive committee, thirteen commissions performing various assigned responsibilities, the Thailand Olympic Academy and the Olympic Athletes Club. According to the Olympic Charter, the members of the executive committee are elected from the general assembly of the NOCT. The members of the general assembly include 33 representatives from sports organizations, one IOC member, one Olympian, who can reinforce the effectiveness of the NOCT and render distinguished services to the cause of sport and Olympism.

The National Olympic Committee of Thailand Executive Board comprised of 25 members; The President, four Vice Presidents Secretary General, IOC member for Thailand and 19 members by as an one female. Recently, the Executive Members of NOCT were elected to join with the Olympic Council of Asia (OCA) commissions since April 2007 as follows:

Major General Charouck Arirachakaran: OCA Vice President.

Professor Chareon Wattanasin: OCA Rules and Regulations Commission.

Mr. Preeda Rodphothong: OCA Cultural and Olympic Education Commission.

Professor Dr. Supitr Samahito: OCA Women and Sport Commission.

Mr. Pipat Paniangvait: OCA Sports Commission.

Dr. Varin Tausupasiri: OCA Medical Commission.

Dr. Thana Chaiphasit: OCA Treasure Commission.

\subsection{Olympic Games}

NOCT joined 15 Olympic Games with 7 gold medals, 4 silvers and 11 bronzes (Table 1) Olympic Games 19522012 participation of Thai contingent.

\subsection{Asian Games}

Thai contingents have participated to all Asian Games since 1950 till 2014 and hosted 4 times: Asian Games V 1996, Asian Games VI 1970, Asian Games VIII 1978, Asian Games XIII 1998, and Number of Thai contingents' 
participation has been shown on Table 2.

Table 1. Participations and medals in the summer Olympic Games of Thai contingents.

\begin{tabular}{|c|c|c|c|c|}
\hline \multirow{2}{*}{ No. } & \multirow{2}{*}{ Year } & \multicolumn{2}{|c|}{ Host } & \multirow{2}{*}{ Medal } \\
\hline & & City & Country & \\
\hline 15 & 1952 & Helsinki & Finland & First participated at the Olympic Games \\
\hline 16 & 1960 & Melbourne & Australia & - \\
\hline 17 & 1964 & Rome & Italy & - \\
\hline 18 & 1964 & Tokyo & Japan & - \\
\hline 19 & 1968 & Mexico City & Mexico & - \\
\hline 20 & 1972 & Munich & Canada & - \\
\hline 21 & 1976 & Montreal & Canada & 1 bronze from boxing \\
\hline 23 & 1984 & Los Angeles & U.S.A. & 1 silver from boxing \\
\hline 24 & 1988 & Seoul & Korea & 1 bronze from boxing \\
\hline 25 & 1992 & Barcelona & Spain & 1 bronze from boxing \\
\hline 26 & 1996 & Atlanta & U.S.A. & 1 gold, 1 bronze from boxing \\
\hline 27 & 2000 & Sydney & Australia & $\begin{array}{l}1 \text { gold, } 1 \text { bronze from boxing } \\
\text { and } 1 \text { bronze from weightlifting }\end{array}$ \\
\hline 28 & 2004 & Athens & Greece & $\begin{array}{l}\text { 3 gold, } 1 \text { silver, } 4 \text { bronze medal } \\
\text { (1 gold from boxing and } 2 \text { gold from weightlifting-1 silver from } \\
\text { boxing - } 1 \text { bronze from boxing, } 1 \text { bronze from weightlifting and } 1 \\
\text { bronze from taekwondo) }\end{array}$ \\
\hline 29 & 2008 & Beijing & China & $\begin{array}{l}2 \text { gold, } 2 \text { silver medal } \\
\text { (1 gold from boxing and } 1 \text { gold from weightlifting }-1 \text { silver from } \\
\text { boxing }-1 \text { silver from taekwondo) }\end{array}$ \\
\hline 30 & 2012 & London & Great Britain & $\begin{array}{c}2 \text { silver, } 1 \text { bronze medal } \\
\text { (1 silver from weightlifting }-1 \text { silver from boxing and } 1 \text { bronze from } \\
\text { taekwondo) }\end{array}$ \\
\hline
\end{tabular}

Table 2. Participations and medals in the Asian Games of Thai contingents.

\begin{tabular}{|c|c|c|c|c|c|c|c|}
\hline \multicolumn{2}{|r|}{ Asian Games } & \multicolumn{2}{|c|}{ Host } & \multicolumn{3}{|c|}{ Medal } & \multirow{2}{*}{$\begin{array}{c}\text { Ranging } \\
\text { No. }\end{array}$} \\
\hline No. & Date & City & Country & Gold & Silver & Bronze & \\
\hline 1 & 4-11 March 1950 & Delhi & India & - & - & - & - \\
\hline 2 & 1-9 May 1954 & Manila & Philippines & - & - & - & - \\
\hline 3 & 24 May-1 June 1958 & Tokyo & Japan & - & 1 & 3 & 4 \\
\hline 4 & 24 August-4 Sep 1962 & Jakarta & Indonesia & 2 & 5 & 5 & 7 \\
\hline 5 & 9-20 December 1966 & Bangkok & Thailand & 12 & 12 & 11 & 3 \\
\hline 6 & 9-20 December 1970 & Bangkok & Thailand & 9 & 17 & 13 & 3 \\
\hline 7 & 1-3 September 1974 & Tehran & Iran & 4 & 2 & 8 & 8 \\
\hline 8 & 9-20 December 1978 & Bangkok & Thailand & 11 & 12 & 19 & 5 \\
\hline 9 & 19 Nov-5 Dec 1982 & Delhi & India & 1 & 5 & 4 & 12 \\
\hline 10 & 20 Sept-5 Oct 1986 & Seoul & Korea & 3 & 10 & 13 & 7 \\
\hline 11 & 22 Sept-7 Oct 1990 & Beijing & China & 2 & 7 & 8 & 9 \\
\hline 12 & 2-6 October 1994 & Hiroshima & Japan & 3 & 9 & 14 & 12 \\
\hline 13 & 6-20 December 1998 & Bangkok & Thailand & 24 & 36 & 40 & 4 \\
\hline 14 & 29 Sep-14 Oct 2002 & Busan & Korea & 14 & 19 & 10 & 6 \\
\hline 15 & 1-15 December 2006 & Doha & Qatar & 13 & 15 & 26 & 5 \\
\hline 16 & 12-27 November 2010 & Guangzhou & China & 11 & 9 & 32 & 9 \\
\hline 17 & 19 Sept-4 Oct 2014 & Incheon & South Korea & 12 & 7 & 28 & 6 \\
\hline
\end{tabular}




\subsection{SEA Games}

The same as Asian Games, Thai contingents have participated since 1959 to 2015 totally 28 times and hosted 6 times at Table 3-Participations and Medals in SEA Games of Thai contingents.

\subsection{Target Groups of Sport Development and Promotion in Thailand}

Olympic Movement in Thailand along with Sport Master Plan [2012-2016] intend to promote the better quality of lives of citizen through public and private sector concerning with sport. The target groups of populations are

1) Children and youths, gaining sport knowledge through the development plan for fundamental sport. They will recognize basic skill of playing and watching sport, within educational system. Ministry of Education and Physical Education Department and Institute of Physical Education will handle and the outside educational system runs by SAT.

2) General Citizen, the development of sport passes through the development plan for mass sport as better health is the target. Ministry of Tourism and Sport and Ministry of Health and also SAT handle this plan.

3) Elite Sport developed to the top cream through the development plan for elite sport at all levels. SAT,

Table 3. Participations and medals in SEA Games of Thai contingents.

\begin{tabular}{|c|c|c|c|c|c|c|c|}
\hline \multirow{2}{*}{ No. } & \multirow{2}{*}{ YEAR } & \multicolumn{2}{|c|}{ Host } & \multicolumn{3}{|c|}{ Medal } & \multirow{2}{*}{$\begin{array}{c}\text { Ranging } \\
\text { No. }\end{array}$} \\
\hline & & City & Country & Gold & Silver & Bronze & \\
\hline 1 & 1959 & Bangkok & Thailand & 35 & 26 & 15 & 1 \\
\hline 2 & 1961 & Yangon & Myanmar & 21 & 18 & 22 & 2 \\
\hline 3 & 1963 & Kuala Lumpur & Malaysia & 38 & 33 & 35 & 1 \\
\hline 4 & 1967 & Bangkok & Thailand & 77 & 48 & 40 & 1 \\
\hline 5 & 1969 & Yangon & Myanmar & 32 & 35 & 45 & 2 \\
\hline 6 & 1970 & Kuala Lumpur & Malaysia & 44 & 27 & 38 & 1 \\
\hline 7 & 1973 & Singapore & Singapore & 47 & 24 & 28 & 1 \\
\hline 8 & 1975 & Bangkok & Thailand & 80 & 45 & 39 & 1 \\
\hline 9 & 1977 & Kuala Lumpur & Malaysia & 37 & 35 & 33 & 2 \\
\hline 10 & 1979 & Jakarta & Indonesia & 50 & 46 & 29 & 2 \\
\hline 11 & 1981 & Manila & Philippines & 62 & 45 & 41 & 2 \\
\hline 12 & 1983 & Singapore & Singapore & 49 & 40 & 38 & 3 \\
\hline 13 & 1985 & Bangkok & Thailand & 93 & 65 & 59 & 1 \\
\hline 14 & 1987 & Jakarta & Indonesia & 63 & 58 & 67 & 2 \\
\hline 15 & 1989 & Kuala Lumpur & Malaysia & 62 & 63 & 66 & 3 \\
\hline 16 & 1991 & Manila & Philippines & 72 & 80 & 71 & 3 \\
\hline 17 & 1993 & Singapore & Singapore & 63 & 70 & 63 & 2 \\
\hline 18 & 1995 & Chiangmai & Thailand & 157 & 98 & 91 & 1 \\
\hline 19 & 1997 & Jakarta & Indonesia & 83 & 97 & 77 & 2 \\
\hline 20 & 1999 & Bandar Seri Begawan & Brunei & 65 & 48 & 56 & 1 \\
\hline 21 & 2001 & Kuala Lumpur & Malaysia & 103 & 86 & 89 & 2 \\
\hline 22 & 2003 & Hanoi, Hojimin & Vietnam & 90 & 93 & 98 & 2 \\
\hline 23 & 2005 & Manila & Philippines & 87 & 78 & 118 & 2 \\
\hline 24 & 2007 & Nakon Ratchasima & Thailand & 183 & 123 & 103 & 1 \\
\hline 25 & 2009 & Vientiane & Laos & 86 & 83 & 97 & 1 \\
\hline 26 & 2011 & Jakarta, Palembang & Indonesia & 109 & 100 & 120 & 2 \\
\hline 27 & 2013 & Nay Pyi Taw & Myanmar & 107 & 94 & 81 & 1 \\
\hline 28 & 2015 & Singapore & Singapore & 95 & 83 & 69 & 1 \\
\hline
\end{tabular}


NOCT, NFs and PFs handle this target group.

4) Professional Athletes, top calibrate of elite sportsmen and women will be larger to professional athletes through the development plan for professional athletes through the development plan for professional sport by SAT and NFs.

5) Sport technical, the development of sport science and technology will be done according to the plan directions by Bureau of University and SAT.

6) Sport personal, sport administrators, coacher, referees will be developed and promoted under the development plan for sport administration by NOCT, NFs, PFs and SAT.

\section{Corporate Governance on the National Olympic Committee of Thailand}

Corporate Governance on the NOCT under the Royal Patronage of H. M. the King. The conduct of the NOCT is required to follow the Olympic Charter strictly: otherwise the IOC can take appropriate measures to act upon possible misconducts performed by the NOCT. Hence several rules governing the NOCT and their members follow the Olympic Charter, for example, the composition of the NOCT, the recognition of the NOCT member, the acquisition of the NOCT executive committee, the responsibility of the NOCT executive committee, and the general operations of the NOCT. With a clear and well establish charter, and responsibilities effectively and efficiently. As a result, the NOCT acts upon the guidelines provided by The Governance in Sport Working Group in 2001.

Moreover, the NOCT has divided its tasks, roles, and responsibilities to thirteen commissions. The thirteen commissions include: (NOCT, 2013) [8].

1) Office of the Secretariat Commission is mainly responsible for monitoring and assisting.

2) Olympic Solidarity Commission is mainly responsible for planning and developing a financial strategy of the NOCT for Olympic Solidarity received from the IOC.

3) Marketing and Privilege Commission is mainly responsible for reviewing and studying possible sponsorships to finance the NOCT.

4) Sport for All Commission is responsible for promoting sports practice for public interest.

5) Rules and Laws Commission is responsible for drawing up rules and laws governed by the NOCT.

6) Information and Technology Commission is responsible for collecting and circulating important and interesting news, statistics, and knowledge relating to sports, the Olympic Movement, and Olympism.

7) Sports Commission is responsible for sending delegates to participate in the international competitions.

8) Medical and Sport Science Commission is responsible for planning for appropriate intervention of medical doctors and sports scientists during the preparation phase of athletes before competitions to ensure maximum benefit for athletes and the NOCT.

9) National Sports Associations and Media Relationships Commission is responsible for coordinating is responsible for auditing the budget of the NOCT.

10) Evaluation Commission is responsible for evaluation policies of the NOCT.

11) Sport for Elite Development Commission is responsible for finding, training, coaching, and maintaining international competitions medalists.

12) Women and Sport Commission is responsible for promoting sports in women and for ensuring gender equality in sports.

13) Policy and Monitoring Commission is responsible for policy making, monitoring, and Evaluation policies of the NOCT.

The demarcation should render the NOCT to be highly productive. It is obvious from Thailand's post-Olympic history that Thailand has Asian Games. However, the success of Thai athletes is at junior level. In the 2010 Youth Olympic Games in Singapore, Thailand won four gold medals and ranked 14th of the medal table. But in previous Olympic Games Thailand has never enjoyed more than three gold medals in a single Olympic Games, and the best place for Thailand was 25th in Athens 2004. This problem is widely recognized in Thailand where Thailand has excellent junior athletes but few elite senior athletes. Good corporate governance would provide a solution to the problem.

CG relates to how an organization morally operates in its challenging situation. Personnel are one of the most critical factors, if not the most important factor, affecting good CG. Though the NOCT has its clear demarcation and delegates its tasks to thirteen commissions, several commissions and delegates its tasks to thirteen commis- 
sions, several commissions are chaired by the same person. As a result, the demarcation has little effect. For example, Office of the Secretariat Commission, Olympic Solidarity Commission, and Marketing and Privilege Commission are also chaired by one person. Technically, several commissions can be chaired by one person. Three problems can occur when one person chairs several commissions, the first problem is ineffectiveness. Given the huge responsibilities of each commission, it is hard to see how these commissions can be run at their most effectiveness. Secondly, the NOCT lacks accountability because the commissions shared by one person many quarrel about their real responsibilities among commissions. Lastly, conflicts of interests many occur more easily because of more power obtained from chairing more commissions.

This problem may arise because Thailand does not have enough pool of interested and qualified candidates for being a chair. This can be resolved by promoting the significance of Olympism to our next generation. Moreover, poor transitions form junior level to senior level can result from poor coordination and limited future career for Thai athletes.

Moreover, several member of the NOCT executive committee have been a member for quite some time. The need for new generations is intense. Thailand is now in the transition of chairperson or president of sports organizations form the old generations who often are retired military generals or bureaucrats to new generations who often are more adept to changes. The research Foreman (2003) [9] found that sports organizations are less effective if managed by elder board members and meet infrequently. Fortunately, the NOCT executive committee will soon consist of executive members from young generations who are passionate in sports. Though they are inexperienced, effective and frequent meetings help they understand the rules of the games.

Equally important with personnel, structure is another area that the NOCT lacks because it does not have a clear organizational structure and authority or means to exert its influence on its members as it may hope for. While the IOC can exercise its full authority on the NOCs, the NOCT cannot exert full authority on its sport organization members due to several reasons. The first reason is the conflicts of interest. The NOCT has several responsibilities, but the most important one is to send athletes rests upon sport organizations which are varied from organization to organization. Many sport organizations do not establish certain rules or criteria in the selection process, while some sports organizations often suddenly change their selection criteria without any prior notice and reasonable explanations. This is, of course, an act against good governance. The NOCT can only reprimand the wrong-doing sports organizations at best. It is argued with certain number of notices given by NOCT; the NOCT should reserve its right not to send delegates from sports organizations to participate in major international competitions. By doing so, the NOCT reduces the possibility of obtaining more medal s from competitions which is against the interest if Thai people, but by not banning wrongdoing sports organizations, the NOCT cannot promote the principle of CG on sports organizations and may even promote wrong doings.

Therefore, the NOCT should find its role between sports organizations member and the Sports Authority of Thailand (SAT) which acts as a government agency providing funding for its sports organizations members. As a result, the NOCT can exert its influence on sports organizations. Without its clear structure and means to exert it influence on sports organizations, it is unlikely that sport organizations will hear from the NOCT no matter how good the advice the NOCT offers. With the drawbacks on its personnel and structure, the NOCT cannot hope for their best outcome. Good practice of corporate governance, i.e. by selecting and strictly enforcing rules, is required for the NOCT.

Olympism offers not only a way to best practice in CG but an effective management in the NOCT. The core values of excellence, friendship, and respect emphasize on the need of brilliant personnel with a strong passion, and promote better working culture among organizations through mutual understanding and expectation. Without a doubt, Olympism is fundamental of good governance.

\section{Conclusions}

The needs for CG have never been greater, especially for the IOC and the NOCs. In a highly competitive and morally deficit economy, several regulations are enacted to ensure the best possible practice among business corporations. However, the IOC and the NOCs are a monopoly in the sports domain and in a highly profitable industry. They are not required to change from competition however they are required to reform according to their very core value which is integrity. As a result, the urgency of CG for the IOC and the NOCs is more intensified to set up examples for business corporations.

The NOCT, as a member of the IOC, needs to practice CG to ensure the maximum benefit of their stakehold- 
ers who mainly are athletes and the citizens of Thailand. The Governance in Sport Working Group (2001) [6] established nine statements of principle for good CG of which the NOCT could mostly follow. However, we found its limitations on the practice CG due to personnel and structure. The NOCT lacks enough qualified and interested candidates, and it does not have a clear organizational structure which can exert influence on its members. As a result, it should promote Olympism to the next generation and develop a role among different partners so that the NOCT can exercise its authority with appropriate measures to wrongdoers.

Olympism and the Olympic Movement in Thailand along with the National Sport Development Plan as the Master Plan, sport activities in Thailand flow along side by side with public and private sectors concerning sport under the same umbrella. Chain of flow crisis crossing has made Thai people try to support each other for the improvement of quality of lives and try to support each other for the improvement of quality of lives and people's healthy. This happening is proved by hosting the Asian Games XIII successfully.

The reason we wrote the above essay was to inform everyone what the NOCs should really do and not divests its capacity, resources, time and funds to carry out non-core business. Some of this non-core business, such as teaching values, belongs to the government and in particular to the Ministry of Education, to religious organizations, parents, etc.

We find that in today's world people are not focus and just jump on to the band wagon to carry out tasks that are already being carried out efficiently and effectively by others are competent and relevant experts.

We often ask whether the sports people are saying that the parents, teachers, professors are not educating the youths of the world on values? If they are not, then why not? If they are, do we need to duplicate and interfere in their core business, which is education, where as our core business is participation in sports?

To us, sports education is playing and competing in sports, not teaching in class rooms. When youths compete with each other, the practice of sport values such as fair play and sportsmanship is forgotten. They are often encouraged by their coaches and sports officials to win at all cost even by cheating or violence.

We were at the Singapore 28th SEA Games (5 to 16 June 2015) and we were utterly disgusted by the bias judging and refereeing and the dirty play by some of the athletes. We say let's not be hypocrites and try to show the world that we are good and pure when actually, we are not that pure and good, because we are human beings after all.

We believe that the circumstances of good cooperation between national and international sport organizations will achieve the objectives of Olympism. The Movement under scopes and directions of sport master plan will fruitfully fertile to children, youths and citizens with good physical and mental health, living peacefully with fraternity in society by means of Olympism and Olympic Movement. We hope that Thailand can pave the path to host Summer Olympic Games in the near future.

\section{References}

[1] Coubertin, P. (1997) The Seventh Olympiad (Antwerp 1920). In: Müller, N., Ed., Pierre de Coubertin 1863-1937Olympism: Selected Writings. International Olympic Committee, Lausanne, 2, 471-476.

[2] International Olympic Committee (1994) 1894-1994-The International Olympic Committee-One Hundred Years: The Idea-The Presidents—The Achievements. International Olympic Committee, Lausanne, Switzerland.

[3] Mitton, T. (2002) A Cross-Firm Analysis of the Impact of Corporate Governance on the East Asian Financial Crisis. Journal of Financial Economics, 64, 215-241.

[4] Julio, H. (2003) Cole Is Professor of Economics at Universidad Francisco Marroquin. Laissez-Faire, 23, 276 p.

[5] Foreman, J. (2003) Corporate Governance Issue in Professional Sport. http://www.sportbusinesscentre.com/wp-content/uploads/2007/11/Foreman172.pdf

[6] Governance in Sport Working Group (2001). Brussels. http://www.fia.com/sites/default/files/basicpage/file/governance_sport.pdf

[7] Burger and Goslin (2005) Compliance with Best Practice Governance Systems by National Sports Federations in South Africa. Unpublished Master's Thesis in Business Administration, University of Pretoria, Pretoria.

[8] National Olympic Committee of Thailand (2013) NOCT Charter 2013, National Olympic Committee of Thailand, Bangkok, No. 13, 30-33.

[9] Fridman, 1999 and Zakus, 2000. The Social Responsibility of Business Is to Increase Profit. New York, 32-33. 


\section{Legends}

IOC: International Olympic Committee

OCA: Olympic Council of Asia

SEA: South East Asian

NOC: National Olympic Committee

NOCT: National Olympic Committee of Thailand

SAT: Sports Authority of Thailand

CG: Corporate Governance

SGB: Sports Governing Bodies

IFs: International Sport Federation

AFs: Asian Sports Federation

NFs: National Sports Federation

PFs: Provincial Sports Federation 